\title{
Simulations of Smoke Flow Fields in a Wind Tunnel under the Effect of an Air Curtain for Smoke Confinement
}

\section{Long-Xing Yu}

Email: Longxing.Yu@UGent.be

Chongqing University, Faculty of Urban Construction and Environmental Engineering, Chongqing, China

Ghent University - UGent, Dept. of Flow, Heat and Combustion Mechanics, Ghent, Belgium

\section{Tarek Beji}

Email: Tarek.Beji@UGent.be

Ghent University - UGent, Dept. of Flow, Heat and Combustion Mechanics, Ghent, Belgium

\section{Setareh Ebrahim Zadeh}

Email: Setareh.Ebrahimzadeh@UGent.be

Ghent University - UGent, Dept. of Flow, Heat and Combustion Mechanics, Ghent, Belgium

\section{Fang Liu}

Email: drliufang@126.com

Chongqing University, Faculty of Urban Construction and Environmental Engineering, Chongqing, China

Fax number: +862365126160

Tel.: +86 13618371808

\section{Bart Merci}

Email: Bart.Merci@UGent.be

Ghent University - UGent, Dept. of Flow, Heat and Combustion Mechanics, Ghent, Belgium 
Simulations of Smoke Flow Fields in a Wind Tunnel under the Effect of an Air Curtain for Smoke Confinement

\begin{abstract}
Computational Fluid Dynamics (CFD) simulation results, obtained with Fire Dynamics Simulator (FDS 6.0.1), are presented in order to analyze the performance of an air curtain in blocking fire-induced smoke in a tunnel configuration. The flow and temperature fields are discussed for different air curtain jet velocities and for a range of smoke inlet temperatures. The key objective is the determination of the effectiveness of a vertical air curtain in blocking the fire-induced smoke spreading downstream of the air curtain, as function of the momentum of the air curtain. The results are presented in non-dimensional form, in terms of a 'momentum ratio' $R$, defined as $R=\frac{\rho_{j} A_{j} V_{j}{ }^{2}}{\rho_{s} A_{s} V_{s}{ }^{2}}$. This is the ratio of the vertically downward air curtain momentum to the horizontal smoke layer momentum at the position of the air curtain. This allows interpretation of the results, obtained at reducedscale, in full-scale configurations. The smoke blocking is quantified by means of sealing effectiveness $E$, defined as one minus the ratio of the average temperature increase in the region downstream of the air curtain to the average temperature increase in the same region without activated air curtain. For small values of $R$, the sealing effectiveness $E$ increases as the momentum ratio $R$ increases. A maximum sealing effectiveness, $E \approx 60 \%$, is attained for $R=8-10$. Higher values of $R$ lead to less effective sealing because the downward impinging air flow pushes smoke into the downward region. For very high values of $R$ the effectiveness increases again, due to dilution of the smoke pushed in the downward region. Keywords: CFD; FDS; Smoke confinement; Air curtain; Wind tunnel
\end{abstract}




\section{Introduction}

It is well-known that most fire deaths are caused by smoke inhalation. Several techniques have been developed to control smoke and remove heat generated by a fire. One system concerns the use of air curtains to block smoke dispersion during fires [1].

The idea of aerodynamic sealing can be dated to the early twentieth century and was brought forward as early as 1904 [2]. In the past 50 years, the increased awareness for energy saving has led to a widespread use of air curtains, triggering theoretical and experimental research on their sealing ability [3]. One of the major applications of air curtains occurs in preserving low temperatures in the refrigerated storage rooms [4]. The destabilizing factor of the air curtain in such configurations is the stack effect caused by the temperature difference, and thus density difference, between the air inside and outside the room. However, in the context of fire, the transverse force of the fire-induced flow is much stronger than the natural convection infiltration through cold store entrances. Therefore, detailed studies must be carried out to assess the effectiveness of smoke confinement using an air curtain.

In recent years, more and more studies on air curtains appeared in the literature, labeling it as an effective way to confine smoke. Hiroshi et al. [1] conducted a 1/60 small scale experiment to investigate the operation of a single type air shutter in a corridor. They suggested that the air shutter flow based on push-pull principle is an excellent aid for fire defense systems. Guyonnaud et al. [5] discussed air curtain design information based on a reduced-scale experiment. They concluded that geometric extrapolation of the results on the basis of conserving the Euler number is not trustworthy. Utilization of air curtains for heat confinement was also discussed using numerical simulations. Elicer-Cortés et al. [6] 
confirm the efficiency of two double-stream twin-jet air curtains in terms of heat confinement in tunnels by means of experiments and Computational Fluid Dynamics (CFD) results obtained with the code FLUENT, release 6.2. Also the Fire Dynamics Simulator (FDS) [7] has already been used for investigating air curtain flows with CFD. Hu et al. [8] studied confinement of smoke and $\mathrm{CO}$ in channel fires by means of bench experiment and FDS (version 4.0.7). They reported an exponential reduction in gas temperature and CO concentration in the protected zone as the discharge velocity of the air curtain increases. Beside tunnel configurations, air curtains can also be installed at the entrance of a stairwell, as studied by Luo et al [9]. The highest temperature at the entrance of the stairwell was measured under different air curtain velocities. Good agreement was reported of FDS (version5) simulation results with experimental data. In a nutshell, all the studies mentioned indicate that air curtains can be useful for confinement of smoke during a fire. The present study is devoted to the analysis of the performance of an air curtain in the context of potential smoke blocking of fire-induced smoke in a reduced-scale tunnel configuration, using the CFD package FDS (Fire Dynamics Simulator), Version 6.0.1 [7]. Flow and temperature fields are discussed for a range of air curtain discharge velocities and a range of fire heat release rates. Results are presented in a non-dimensional manner, so they can serve as basis for design guidelines. The present CFD simulations also serve as pre-test predictions in preparation of experiments to be carried out in a reduced-scale wind tunnel (the low speed wind tunnel called 'L2B' [10] at Von Karman Institute, Belgium, see Fig. 1), where the flow field and smoke concentration can be measured through the Large Scale Particle Image Velocimetry (LS-PIV) technique [11]. 
Figure 1. Picture of the wind tunnel for the reduced-scale experiments.

\section{General set-up of the simulations}

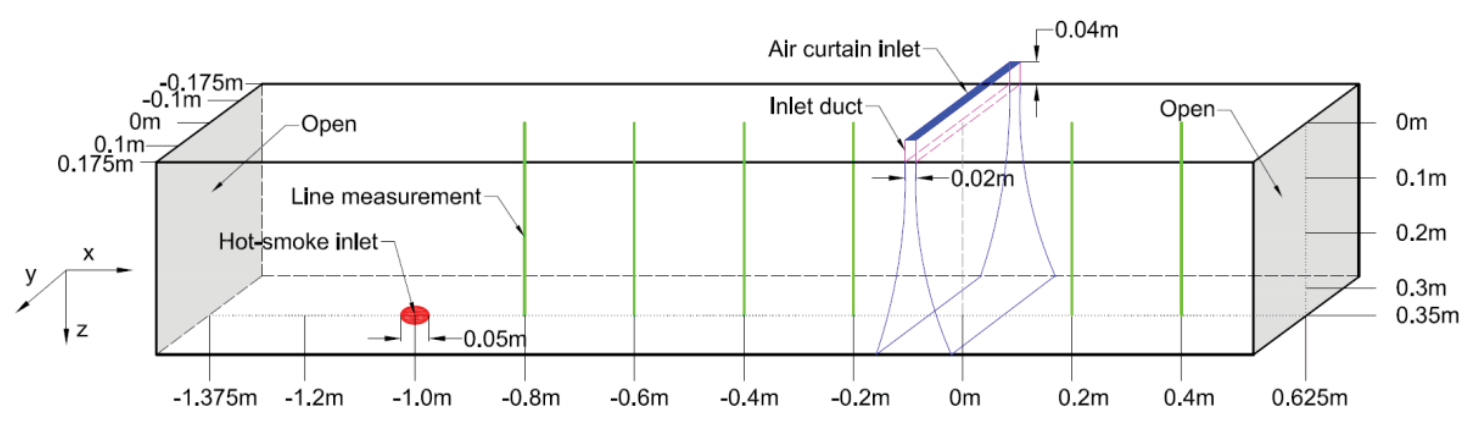

Figure 2. Schematic representation of the test section of low speed wind tunnel 'L2B' at Von Karman Institute (see Fig. 1).

\subsection{Dimensions and boundary conditions}

A schematic view of the geometry of the test section, resembles the wind tunnel section presented in Fig. 1, is provided in Fig. 2. The dimensions of the wind tunnel are $0.35 \mathrm{~m} \times$ $0.35 \mathrm{~m} \times 2 \mathrm{~m}$. The left and right end of the wind tunnel, marked in grey, are open to the 
outside by specifying them to be 'OPEN', which denotes a passive opening to the outside [7]. By default in FDS, ambient conditions are assumed to prevail beyond the 'OPEN' vent. The four other sides are 'solid' boundary conditions, with the temperature fixed at ambient temperature $\left(20^{\circ} \mathrm{C}\right)$, and are referred to as 'INERT' [7], which is the default boundary condition for all solid surfaces in FDS. The initial condition corresponds to ambient conditions without any flow.

In order to resemble as closely as possible the real turbulent planar jet flow with a limited calculation cost, the air curtain injection is created through an inlet duct, marked in purple, so that the velocity inlet boundary condition is imposed upstream of the actual orifice. The duct length is set equal to 1 hydraulic diameter of the air curtain inlet $(4 \mathrm{~cm})$, as a previous study indicated this is sufficient [12]. The air curtain inlet, marked in blue, has a dimension of $35 \mathrm{~cm}$ (length, $\mathrm{L}) \times 2 \mathrm{~cm}$ (width, $\mathrm{W}$ ), resulting in an aspect ratio $\mathrm{AR}=\mathrm{L} / \mathrm{W}$ of $17.5 . \mathrm{A}$ power-law velocity profile [13], resembling the fully developed velocity profile, is imposed at the air curtain inlet. This profile has been determined from a preliminary calculation (not shown here) using a $60 \mathrm{~cm}$ (i.e., approximately 15 hydraulic diameter) long inlet duct [12]. A range of maximum velocities of $(0 \mathrm{~m} / \mathrm{s}-2 \mathrm{~m} / \mathrm{s})$ have been applied. The synthetic eddy method (SEM) [14] is used as inlet boundary condition for turbulence, for a more realistic turbulent jet flow simulation. With this approach, artificial eddies are implemented in FDS by specification of the number of eddies (N_EDDY), the characteristic (integral) eddy length scale (L_EDDY) and the amplitude of turbulent fluctuations (VEL_RMS). In the present study, the values are: N_EDDY $=1120$, L_EDDY $=0.0028 \mathrm{~m}$, and VEL_RMS defined such that the turbulence intensity equals $10 \%$. The detailed set-up of air curtain inlet and the reasons for the chosen parameters of SEM have been investigated in a separate 
study and the reader is referred to the FDS manual [7] and Jarrin's thesis [14] for more detailed information on the SEM technique.

The round hot-smoke inlet, marked in red in Fig. 2, is positioned $1 \mathrm{~m}$ away from the air curtain. It has a diameter of $5 \mathrm{~cm}$ and is flush with the floor. The velocity inlet boundary condition determines the source of hot 'smoke'. Hot air is injected as a top-hat velocity profile, equal to $1 \mathrm{~m} / \mathrm{s}$. Since a detailed simulation of the smoke plume is out of the scope of the present study, this is considered sufficiently accurate and the SEM is not applied at this inlet. In the basic calculations, the hot 'smoke' inlet temperature is $300^{\circ} \mathrm{C}$. This corresponds to a fire source with heat release rate of $0.34 \mathrm{~kW}$. As can be learnt from Froude scaling $\left(\dot{Q}_{m} / \dot{Q}_{f}=\left(L_{m} / L_{f}\right)^{5 / 2}=\lambda_{L}^{5 / 2}\right)$, this corresponds to $1 \mathrm{MW}$ in full scale for a geometrical scale-up factor of 25 . In section 3.4 a sensitivity study on the inlet temperature is presented, including results for $150^{\circ} \mathrm{C}$ and $600^{\circ} \mathrm{C}$ as well. Thus the range of HRR is from $0.21 \mathrm{~kW}$ to $0.49 \mathrm{~kW}$ (corresponding to the range $0.67 \mathrm{MW}-1.44 \mathrm{MW}$ full scale for a geometrical scale-up factor of 25). The densimetric Froude number ( $\mathrm{Fr}=$ $\left.v_{\text {in }} / \sqrt{\left(\Delta \rho / \rho_{a m b}\right) g D}\right)$, which denotes the ratio of inertial to buoyancy forces at the hotsmoke inlet is then $2.58,2.04$ or 1.71 , respectively.

\subsection{Grid resolution and turbulence models}

Uniform cubic cells are used in all simulations, with grid resolution $\mathrm{W} / \Delta=8(\Delta=0.25 \mathrm{~cm})$. This results in 16 cells across the hydraulic diameter of the air curtain inlet, 20 cells across the hydraulic diameter of the hot-smoke inlet and in total $15,904,000$ cells within the computational domain. Parallel calculations are adopted on 32 processors. It has been proven to be sufficiently fine for the simulations at hand [12] and is in line with the 
recommendation made in [15].

In FDS, turbulence is modeled within the Large-Eddy Simulations (LES) framework. The dynamic Smagorinsky turbulence model [16] has been applied in all the simulations, since then no tuning is required for the model parameter $C_{S}$ in the subgrid scale viscosity. A sensitivity study on turbulence modeling is considered beyond the scope of the present paper.

\subsection{Test cases and measurements}

In total, 23 simulations have been carried out (see Table 1 below), for variable air curtain jet velocity $(0-2 \mathrm{~m} / \mathrm{s})$ and hot smoke inlet temperature $\left(150^{\circ} \mathrm{C}-600^{\circ} \mathrm{C}\right)$. The focus of the study is the evolution of the sealing effectiveness of the air curtain as function of the air curtain momentum.

Figure 2 shows the computational domain, as well as the six line measurements made in the symmetry plane in the CFD calculations (marked in green), recording velocity and temperature. They are distributed upstream and downstream of the air curtain inlet, at intervals of $20 \mathrm{~cm}$.

\subsection{Averaged values}

In all simulations, a period of 30 seconds in total is covered. As the LES technique is used, the simulation results are analyzed in the form of averaged values, since instantaneous snapshots can be misleading. Figure 3 presents the evolution of mass flow rate (top) and heat flow rate (bottom) at different cross-sections $(X= \pm 0.1 \mathrm{~m}, \pm 0.2 \mathrm{~m}$ and $\pm 0.3 \mathrm{~m})$, for the two extreme values for the air curtain inlet velocity $(0 \mathrm{~m} / \mathrm{s}$ and $2 \mathrm{~m} / \mathrm{s})$. Regardless the 
operation of the air curtain, it takes about 5 seconds for the hot 'smoke' to reach the measurement point. After that, (quasi) steady state conditions are reached rapidly. For obvious reasons, there are much stronger fluctuations with the air curtain in operation. Nevertheless, a (quasi) steady-state situation can be considered during the last 10 seconds. Therefore, all mean values below have been retrieved as output from the simulations, averaging the results over the last 10 seconds of the total of 30 seconds calculation time.
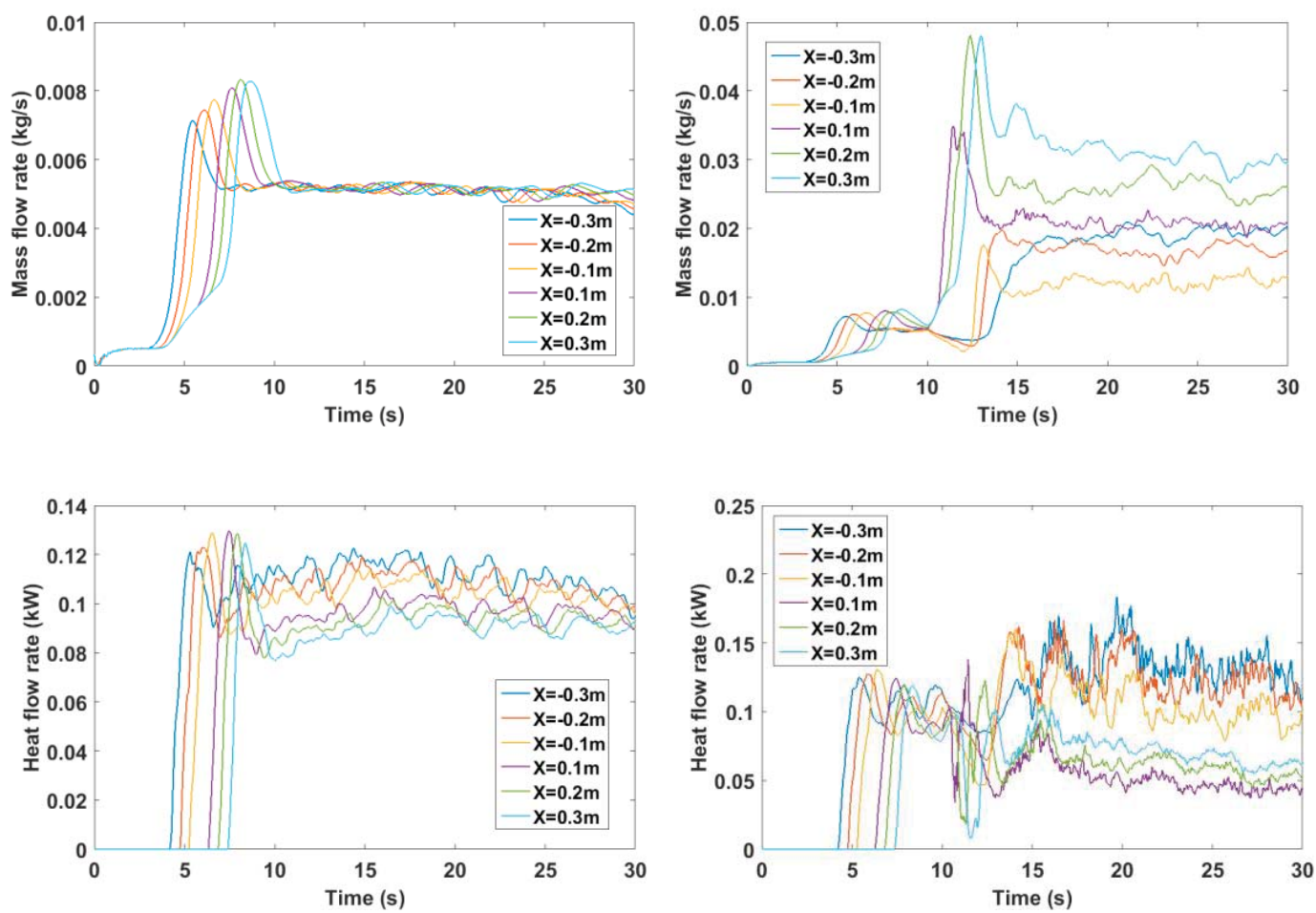

Figure 3. Temporal evolution of mass flow rate (top) and heat flow rate (bottom) at different cross-sections in the absence of an air curtain (left) and for air curtain velocity equal to $2 \mathrm{~m} / \mathrm{s}$ (right). 


\section{Results and discussion}

\subsection{Smoke layer and air curtain momentum}

In the configuration at hand, two basic flows are of fundamental interest, namely the horizontally flowing 'smoke' layer underneath the ceiling and the vertical air curtain flow, which is essentially a planar jet. The interaction of these two basic flows results in a flow field that is far more complex than either of its components.

The horizontal smoke layer motion stems from the smoke plume, driven by the buoyancy of the hot products, impinging onto the ceiling. This is the so-called ceiling jet phenomenon [17], which results in an essentially one-dimensional flow underneath the tunnel ceiling, sufficiently far away from the smoke source.

Figure 4 shows the horizontal velocity and temperature profiles of the smoke layer at the air curtain position $(\mathrm{X}=0)$ for different inlet temperatures of hot smoke plumes, in the absence of an air curtain. Not surprisingly, the temperature increases as the inlet temperature of hot smoke plume increases. Indeed, more energy is injected per unit time into the domain as the smoke inlet temperature increases, keeping all other settings identical: $\quad \dot{Q}_{i n}=\rho_{i n} c_{p}\left(T_{i n}-T_{a m b}\right) A v_{i n}=\frac{p}{R T_{\text {in }}} c_{p}\left(T_{i n}-T_{a m b}\right) A v=\frac{p}{R} c_{p}\left(1-\frac{T_{a m b}}{T_{i n}}\right) A v_{i n}$. Also the horizontal velocity of the smoke layer increases, due to the increased energy injection and the increased buoyancy, enhancing the entrainment into the vertically rising smoke plume and thus adding to the horizontal momentum of the smoke layer underneath the ceiling. The smoke layer depths are approximately the same, namely approximately $0.1 \mathrm{~m}$. 

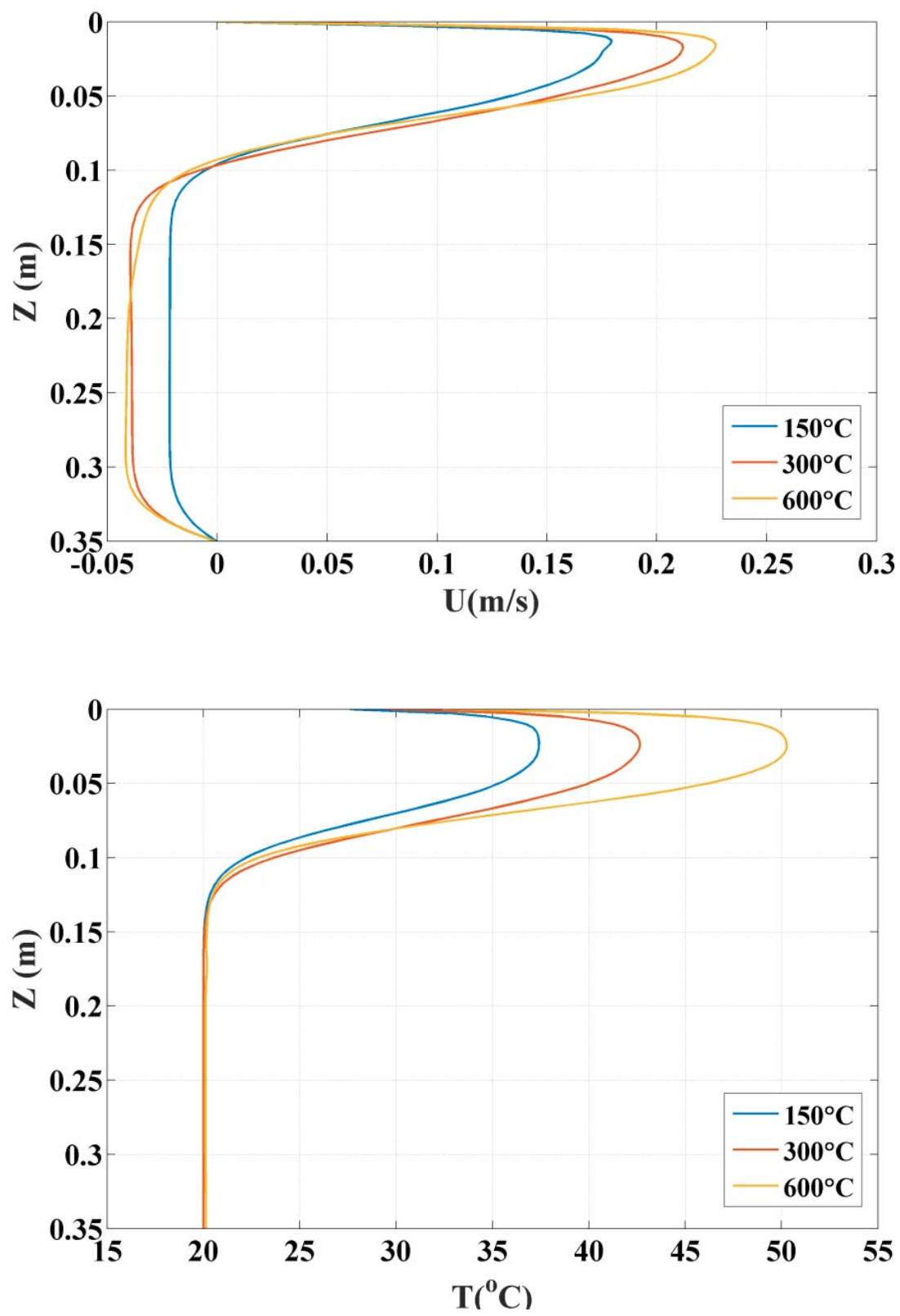

Figure 4. Profiles of mean horizontal velocity (up) and temperature (bottom) in the smoke layer at the air curtain position for different inlet temperatures of hot smoke plume. The air curtain is not activated.

In order to quantify the relative strength of ceiling jet momentum and air curtain momentum, the 'effective momentum ratio' is defined: 


$$
R=\frac{\rho_{j} A_{j} V_{j}^{2}}{\rho_{s} A_{s} V_{s}^{2}}
$$

This is the ratio of the vertically downward air curtain momentum to the horizontal smoke layer momentum at the position of the air curtain. $\rho_{j}$ and $V_{j}$ are the integrated mean mass density, resp. velocity, of the air curtain jet over its width, while $\rho_{s}$ and $V_{s}$ are the integrated mean mass density, resp. velocity, of the smoke layer flow underneath the ceiling over its depth (taken equal to $0.1 \mathrm{~m}$, as mentioned earlier). $A_{j}$ is the area of air curtain inlet, calculated as the width of the air curtain times its length, while $A_{S}$ is the cross-sectional area of celling jet flow, calculated as the tunnel width times the ceiling jet depth.

Table 1 shows the values for $R$ of all the tests in the present study. Table 2 provides the momentums, corresponding to the velocities and temperatures mentioned in table 1 .

Table 1. Effective momentum ratio $R$ (Eq. (1)) for all test cases. Top row: air curtain maximum inlet velocity (in $\mathrm{m} / \mathrm{s}$ ); left column: smoke plume inlet temperature (in ${ }^{\circ} \mathrm{C}$ ).

\begin{tabular}{|c|c|c|c|c|c|c|c|c|c|c|c|}
\hline & $\mathbf{0}$ & $\mathbf{0 . 5}$ & $\mathbf{0 . 7 5}$ & $\mathbf{1}$ & $\mathbf{1 . 2}$ & $\mathbf{1 . 4}$ & $\mathbf{1 . 5}$ & $\mathbf{1 . 6}$ & $\mathbf{1 . 8}$ & $\mathbf{1 . 9}$ & $\mathbf{2}$ \\
\hline $\mathbf{1 5 0}$ & 0 & & 6.11 & 10.87 & 15.65 & 21.30 & 24.45 & 27.82 & & & \\
\hline $\mathbf{3 0 0}$ & 0 & 1.91 & 4.29 & 7.63 & 10.99 & 14.95 & 17.17 & 19.53 & 24.72 & 27.54 & 30.52 \\
\hline $\mathbf{6 0 0}$ & 0 & & 4.11 & & 10.52 & & 16.43 & & & & 29.21 \\
\hline
\end{tabular}


Table 2. Momentum (in $10^{-3} \mathrm{~kg} \cdot \mathrm{m} / \mathrm{s}^{2}$ ) for all test cases.

\begin{tabular}{|c|c|c|}
\hline \multicolumn{2}{|c|}{} & Momentum $\left(10^{-3} \mathrm{~kg} \cdot \mathrm{m} / \mathrm{s}^{2}\right)$ \\
\hline \multirow{3}{*}{$\begin{array}{c}\text { Plume inlet temperature } \\
\left({ }^{\circ} \mathrm{C}\right)\end{array}$} & 150 & 0.44 \\
\cline { 2 - 3 } & 300 & 0.63 \\
\cline { 2 - 3 } & 600 & 0.66 \\
\cline { 2 - 3 } & 0.5 & 1.20 \\
\cline { 2 - 3 } & 0.75 & 2.71 \\
\cline { 2 - 3 } & 1 & 4.81 \\
\cline { 2 - 3 } & 1.2 & 6.93 \\
\cline { 2 - 3 } vir curtain maximum inlet & 1.4 & 9.43 \\
\cline { 2 - 3 } & 1.5 & 10.83 \\
\cline { 2 - 3 } & 1.6 & 12.32 \\
\cline { 2 - 3 } & 1.8 & 15.59 \\
\cline { 2 - 3 } & 1.9 & 17.37 \\
\cline { 2 - 3 } & 2 & 19.25 \\
\hline
\end{tabular}

\subsection{Influence of the air curtain on the flow field}

In this sub-section, the smoke flow fields are discussed for different air curtain jet velocities, setting the smoke inlet temperature equal to $300{ }^{\circ} \mathrm{C}$. It is instructive to carefully examine the effect of the air curtain on the air motion inside the wind tunnel. Obviously, the air motion in the wind tunnel will simultaneously affect the smoke spread and the effectiveness of air curtain.

Figure 5, presenting profiles for mean horizontal velocity in the $x$ direction for variable air curtain jet velocity at different locations in the symmetry plane of the wind tunnel, reveals that the smoke flow field is strongly affected by the air curtain operation. Without the air curtain operational $(\mathrm{V}=0 \mathrm{~m} / \mathrm{s})$, all velocity profiles have an 'Inverted S-shape', i.e., the profiles have a positive value at the top and negative value at the bottom. This is also clearly visible in Fig. 6, showing the mean horizontal velocity contours and mean velocity vector fields in the symmetry plane of the wind tunnel. Thus, the smoke flow field at the right 
hand side of the fire can be divided into 'two zones' with different flow directions (see top figure of Fig. 6): the hot upper layer moves to the right $(U>0)$ and the cold bottom layer moves to the left $(\mathrm{U}<0)$ due to buoyancy (impinging smoke plume onto the ceiling) and entrainment (into the smoke plume). For sufficiently low air curtain jet velocity (e.g., $\mathrm{V}_{j}=$ $0.5 \mathrm{~m} / \mathrm{s}$ ), this qualitative picture does not change (see Figs. 5 and 6).
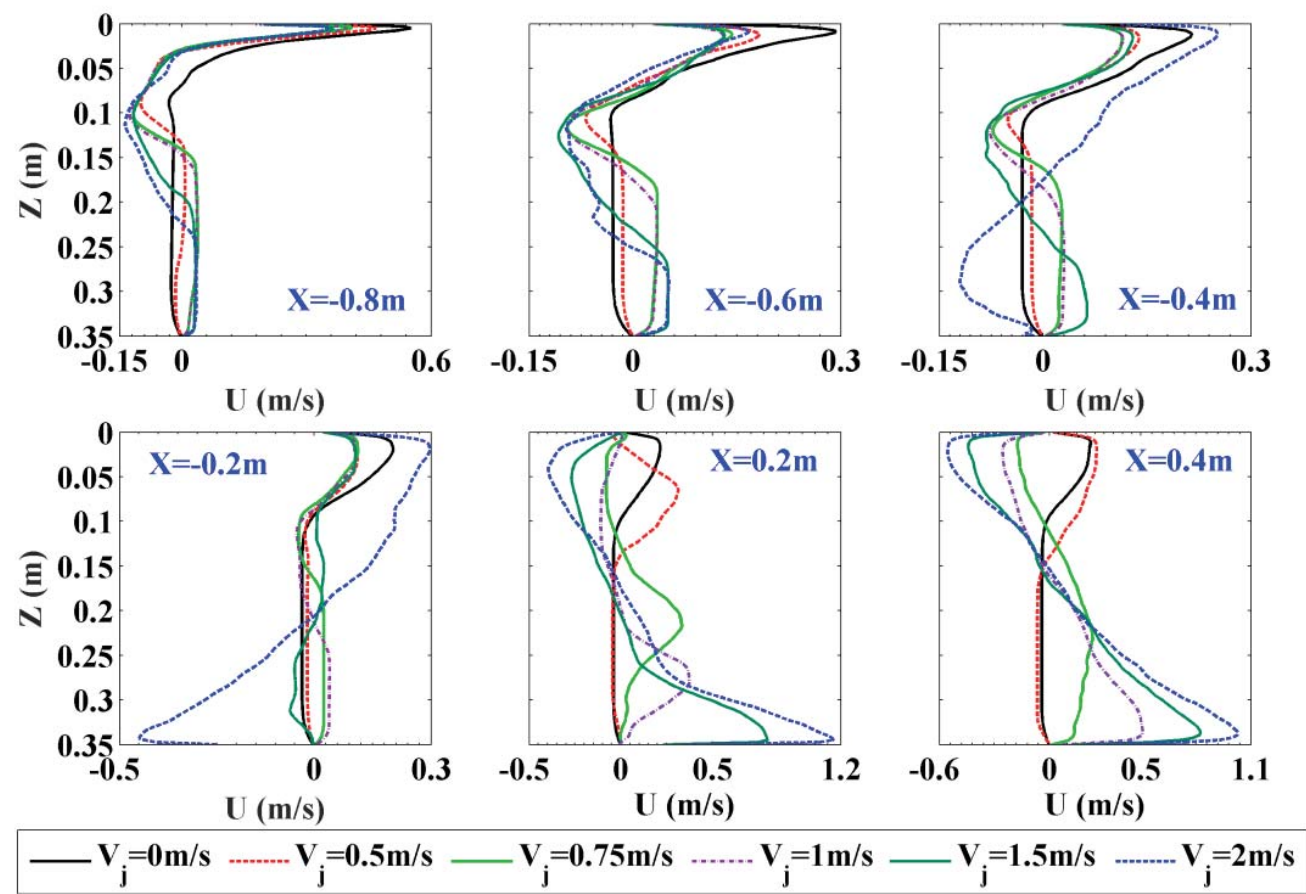

Figure 5. Vertical profiles of mean horizontal velocity at different locations in the symmetry plane of the wind tunnel. $V_{j}$ refers to the air curtain jet velocity (in $\mathrm{m} / \mathrm{s}$ ). Plume inlet temperature equals $300^{\circ} \mathrm{C}$.

However, for higher air curtain velocities, such that the air curtain jet flow impinges on the floor (i.e., $\mathrm{V}_{j}=0.75 \mathrm{~m} / \mathrm{s}$ or higher for the case at hand), the smoke flow field is stratified in 'three zones' in the region between the smoke plume and the air curtain, close to the smoke plume (see the first two sub-figures of Fig. 5). Indeed, the upper and lower layer move to the right $(U>0)$, while the middle layer moves to the left $(U<0)$. Closer to the 
air curtain (at $\mathrm{X}=-0.4 \mathrm{~m}$ and $\mathrm{X}=-0.2 \mathrm{~m}$ for $\mathrm{V}_{j}=2.0 \mathrm{~m} / \mathrm{s}$ and at $\mathrm{X}=-0.2 \mathrm{~m}$ for $\mathrm{V}_{j}=1.5$ $\mathrm{m} / \mathrm{s}$ ), only two layers are observed again, but for a different reason than close to the smoke plume: now the negative velocities near the floor are induced by the impinging jet from the air curtain, not by the entrainment into the smoke plume. The higher the air curtain velocity, the stronger the backward flow towards the fire source becomes.

Behind the air curtain (see the final two sub-figures of Figs. 5), the velocity profiles have an 'S-shape' again for sufficiently high air curtain velocities (i.e., $\mathrm{V}_{j}=0.75 \mathrm{~m} / \mathrm{s}$ or higher for the case at hand), due to entrainment into the air curtain jet $(U<0$ near the ceiling) and the impingement of the jet onto the floor ( $U>0$ near the floor). This is also clearly observed in Fig. 6.

It is mentioned that the recirculation region near the right boundary is not caused by the boundary condition. Rather, it is induced by the air curtain momentum. This has been verified through additional simulations, moving the boundary further away (not shown). 


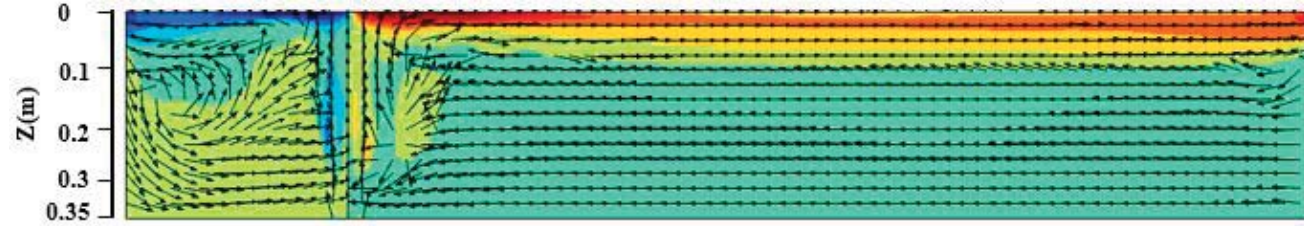

$\mathrm{U}(\mathrm{m} / \mathrm{s})$
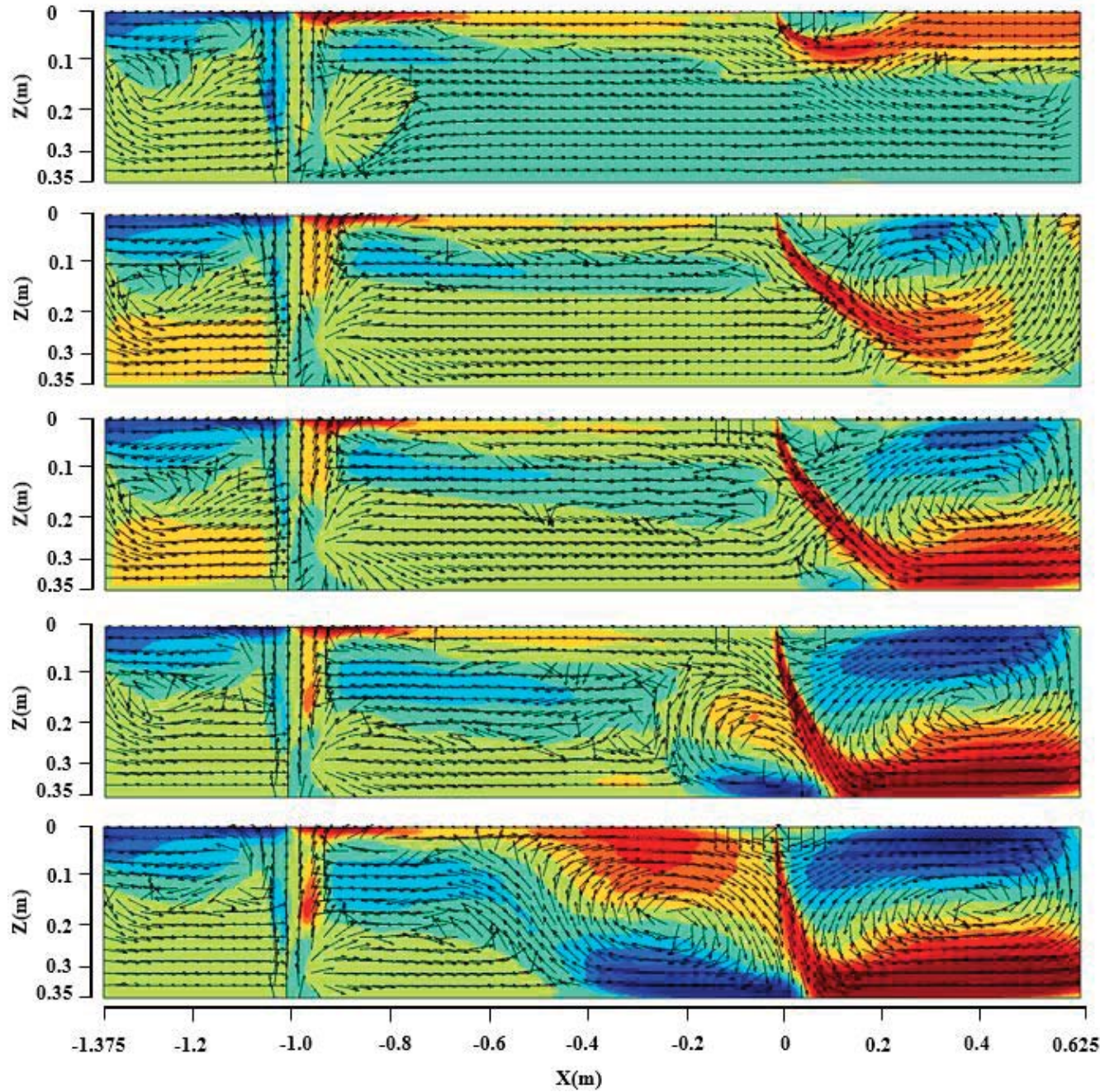

Figure 6. Contours of mean horizontal velocity and mean velocity vectors in the symmetry plane of the wind tunnel. $U>0$ represents flow to the right; $U<0$ represents flow to the left. From top to bottom: $V_{j}=0 \mathrm{~m} / \mathrm{s}, V_{j}=0.5 \mathrm{~m} / \mathrm{s}, V_{j}=0.75 \mathrm{~m} / \mathrm{s}, V_{j}=1 \mathrm{~m} / \mathrm{s}$, $V_{j}=1.5 \mathrm{~m} / \mathrm{s}$ and $V_{j}=2.0 \mathrm{~m} / \mathrm{s}$. Plume inlet temperature equals $300^{\circ} \mathrm{C}$. 
Finally, it is noted that the vertical air curtain flow is deflected by the horizontal momentum of the smoke layer. Obviously, less deflection of the air curtain flow is observed for higher air curtain jet velocity. A detailed quantitative analysis of the jet trajectory and deflection angle is, however, a research study on itself and is considered outside the scope of the present paper.

\subsection{Influence of air curtain on the temperature field}

Fig. 7 shows the mean temperature contours in the symmetry plane of the wind tunnel. The similarity to Fig. 6 is, of course, striking, due to the convective transport of heat with the flow. Fig. 7 reveals that the temperature rise behind the air curtain becomes very small when the air curtain velocity is higher than or equal to $V=0.75 \mathrm{~m} / \mathrm{s}$, which corresponds to $R>4.29$ (see Table 1). The temperature rise behind the air curtain becomes less for higher values of $R$, of course. However, as mentioned in section 3.2, more back-flow with fresh air will move to the fire source as the air curtain velocity (or $R$ ) increases. This may strengthen an under-ventilated fire and is in any case not deemed useful. The air curtain does not introduce heat into the domain, since the injected air is at ambient temperature. A detailed discussion on the sealing effectiveness of the air curtain is shown in section 3.5. 

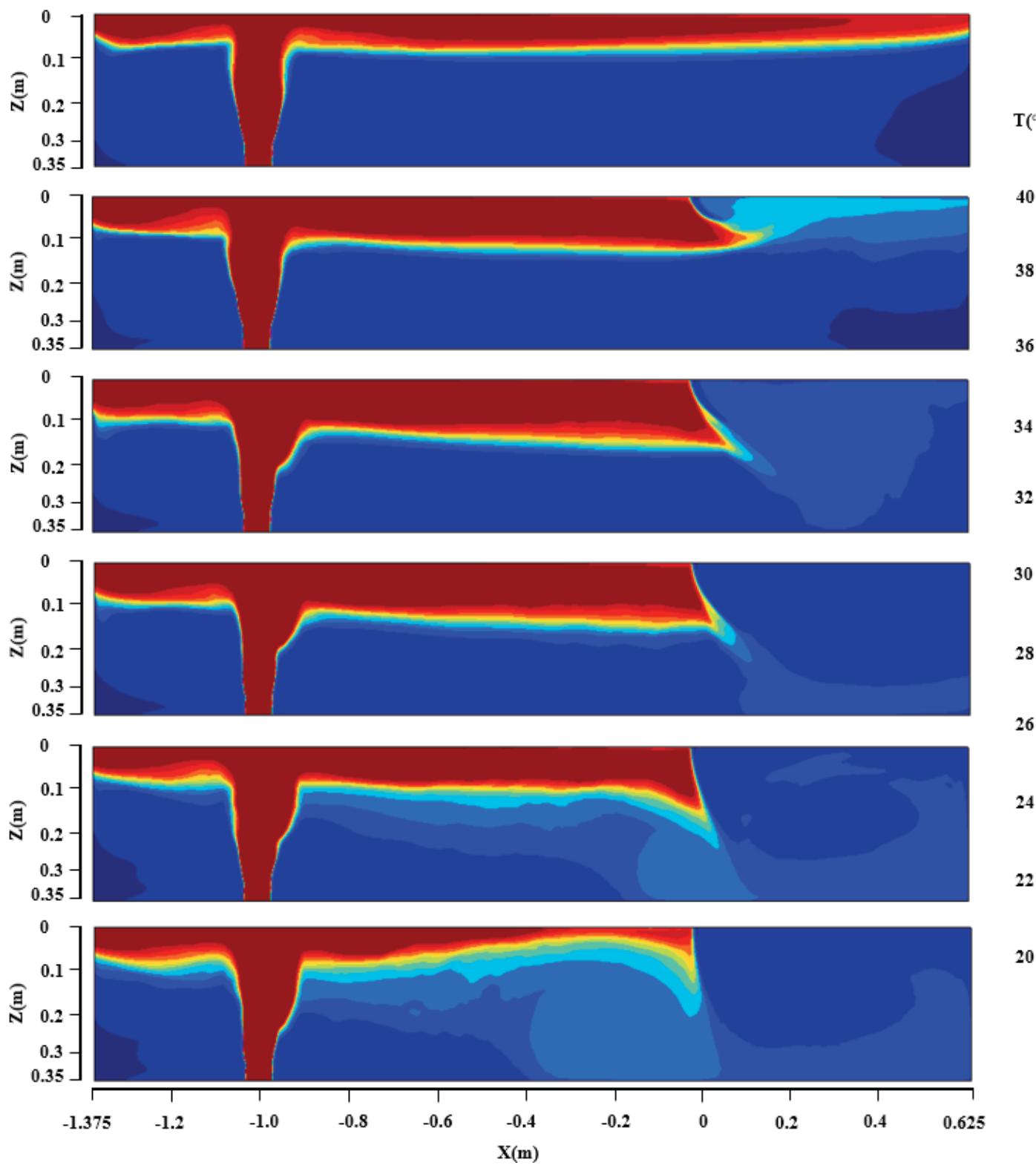

20

Figure 7. Mean temperature contours in the symmetry plane of the wind tunnel. From top to bottom: $V_{j}=0 \mathrm{~m} / \mathrm{s}, V_{j}=0.5 \mathrm{~m} / \mathrm{s}, V_{j}=0.75 \mathrm{~m} / \mathrm{s}, V_{j}=1 \mathrm{~m} / \mathrm{s}, V_{j}=1.5 \mathrm{~m} / \mathrm{s}$ and $V_{j}=2.0 \mathrm{~m} / \mathrm{s}$. Plume inlet temperature equals $300^{\circ} \mathrm{C}$. 

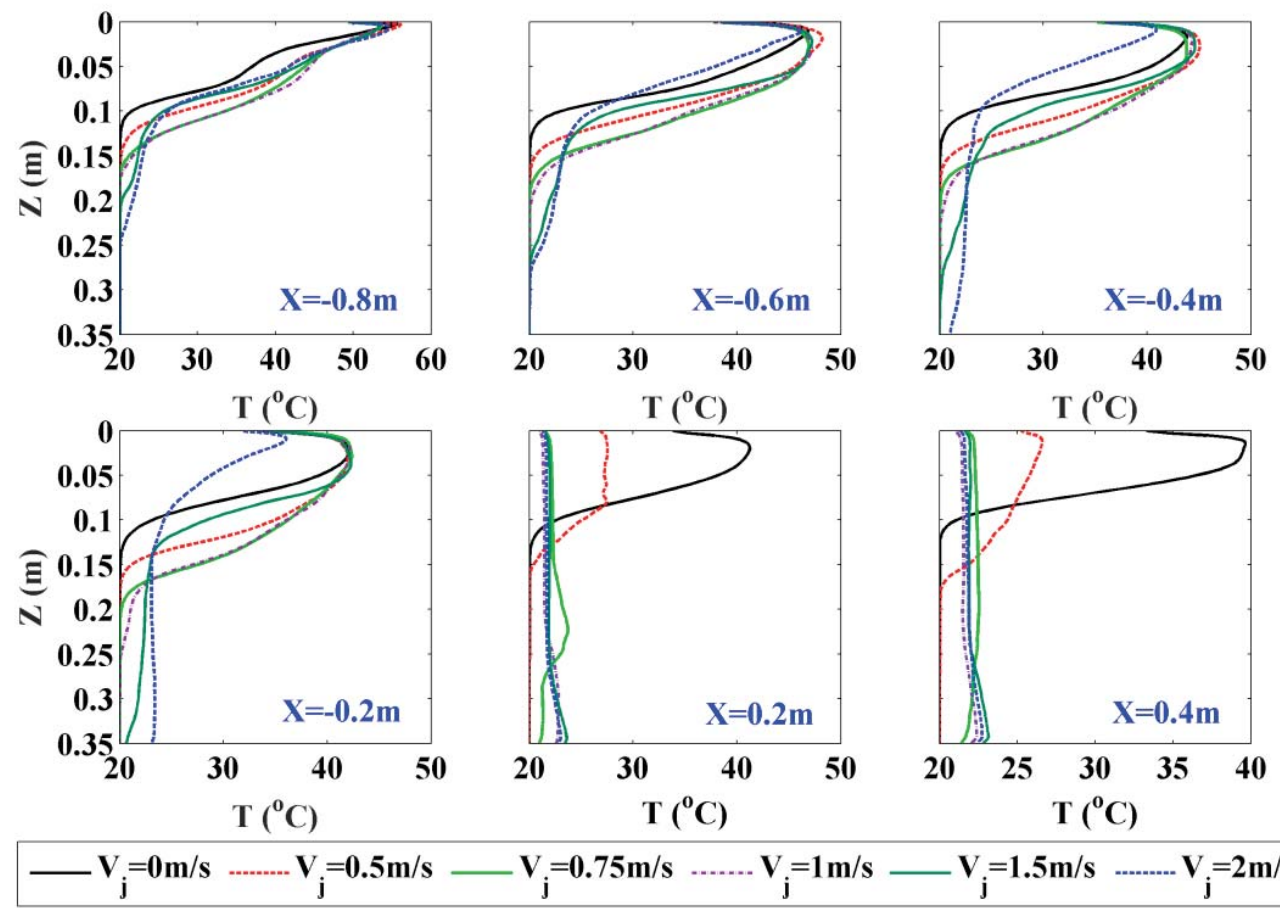

$-V_{j}=1.5 \mathrm{~m} / \mathrm{s} \quad \ldots \ldots-\mathrm{V}_{\mathrm{j}}=2 \mathrm{~m} / \mathrm{s}$

Figure 8. Vertical profiles of mean temperature at different locations in the symmetry plane of the wind tunnel. $V_{j}$ refers to the air curtain jet velocity (in $\mathrm{m} / \mathrm{s}$ ). Plume inlet temperature equals $300^{\circ} \mathrm{C}$.

Figure 8 shows the vertical profiles of mean temperature at the same locations as the mean velocities, shown in Fig. 5. Like the smoke flow field, the temperature field is strongly affected by the air curtain operation. It is clear that, with the air curtain in operation, smoke accumulates in between the fire and the air curtain, even though smoke is flowing out through the left opening of the wind tunnel. Indeed, compared to the case $V_{j}=0 \mathrm{~m} / \mathrm{s}$, the smoke layer thickness increases with increasing air curtain velocity (up to $V_{j}=1 \mathrm{~m} / \mathrm{s}$, i.e., $R=7.63$, see Table 1). This accumulation causes the smoke layer interface, determined based on the second derivative of the temperature profile [15], to descend by approximately $0.05 \mathrm{~m}$ ( $15 \%$ of ceiling height, mean value of the four positions in between the smoke plume and the air curtain), which can be a drawback. For still higher values of $R$, the smoke layer 
thickness decreases again, and temperatures become lower, due to the strong backflow of cold air, as depicted in Fig. 6. More smoke is then also pushed out through the left opening of the wind tunnel. As mentioned above, such back-flow of fresh air towards the fire source is in general undesired, though.

Note that the maximum smoke layer temperature at $X=-0.2 \mathrm{~m}$ (i.e., close to the air curtain) is hardly affected by the presence of the air curtain, unless the air curtain jet velocity is extremely high (see $V_{j}=2 \mathrm{~m} / \mathrm{s}$ in Fig. 7). In other words, there is hardly any cooling effect by the injected cold air $\left(20{ }^{\circ} \mathrm{C}\right)$ from the air curtain as long as the jet velocity is not extremely high (and thus the amount of the back-flow is not excessive).

Also note that the sealing effect is the strongest near the air curtain $(X=-0.2 \mathrm{~m})$, but even close to the smoke source $(\mathrm{X}=-0.8 \mathrm{~m})$ the impact of the air curtain is significant, regardless the air curtain velocity.

The last two sub-figures of figure 8 clearly show that the temperature behind the air curtain is significantly lower, compared to an unobstructed open situation. Note, though, that the temperatures are consistently higher for $\mathrm{V}_{j}=1.5 \mathrm{~m} / \mathrm{s}$ than for, e.g., $\mathrm{V}_{j}=1.0 \mathrm{~m} / \mathrm{s}$ behind the air curtain. We come back to this point in section 3.5.

\subsection{Influence of the smoke plume inlet temperature}

In this subsection, the impact of the hot smoke plume inlet temperature is examined. To that purpose, all the settings are kept identical, except for the inlet temperature for the hot smoke plume, which is set to $150^{\circ} \mathrm{C}$ and $600^{\circ} \mathrm{C}$, respectively (in addition to $300^{\circ} \mathrm{C}$, which has already been discussed above). The air curtain jet velocity is set to $0.75 \mathrm{~m} / \mathrm{s}$, which corresponded to the onset of smoke blocking above. Table 1 reveals that the range of values 
for $R$ is from approximately 4.1 to approximately 6.1. As mentioned in section 3.1, a higher (resp. lower) inlet temperature denotes, essentially, a higher (resp. lower) HRR. However, the main intent here is to vary the smoke layer flow properties (in terms of temperature, velocity and momentum) and investigate their influence on the air curtain, rather than express the findings as a function of the fire size. Indeed, the hot smoke layer momentum can vary strongly for the same HRR value, depending on the tunnel geometry and the geometrical dimensions of the fire. Indeed, the tunnel height and geometrical size of the fire will strongly affect the amount of entrainment into the vertical plume (and thus the temperature and momentum in the impingement region of the ceiling jet), while the width of the tunnel will strongly affect the velocity (and thus momentum), given a certain mass flow rate (and temperature).
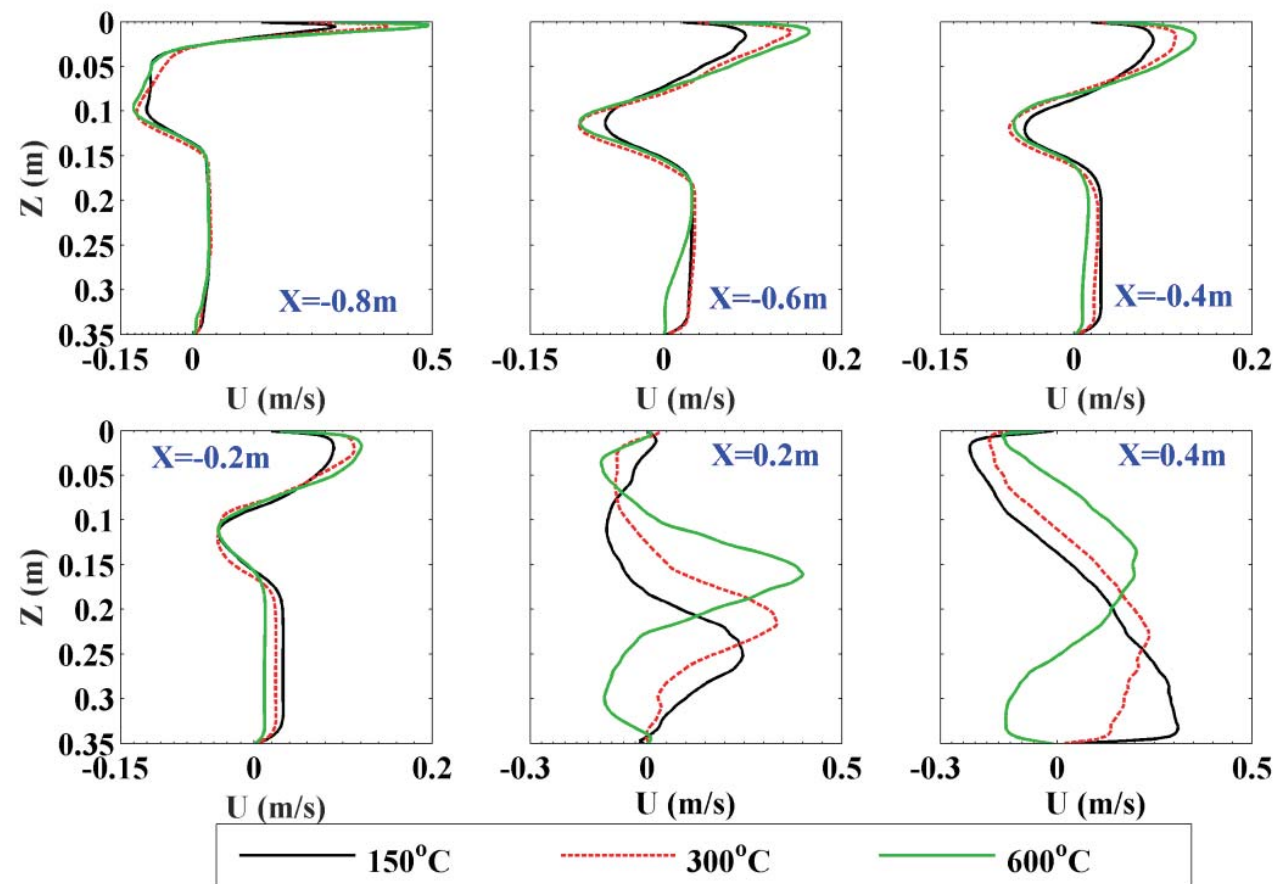

Figure 9. Vertical profiles of mean horizontal velocity at different locations in the symmetry plane of the wind tunnel. The legend refers to the plume inlet temperature (in 
$\left.{ }^{\circ} \mathrm{C}\right)$. The air curtain jet velocity is set to $V_{j}=0.75 \mathrm{~m} / \mathrm{s}$.

Figure 9 presents vertical profiles of mean horizontal velocity at the same locations in the symmetry plane of the wind tunnel as in Fig. 5. In between the smoke plume and the air curtain, slightly higher ceiling jet velocities are observed for the smoke plume with higher inlet temperature, particularly sufficiently far from the air curtain, for the same reasons as explained in Fig. 4. Closer to the air curtain, the blocking effect is visible, as the flow stagnates (compared to the result shown in Fig. 4). At all locations between the smoke plume and the air curtain, the shapes of the velocity profiles are very similar, regardless of the smoke plume inlet temperature. At the locations behind the air curtain, the flow field changes from 'two zones' to 'three zones' when the air curtain can no longer block the smoke, due to the higher smoke momentum induced by the higher plume inlet temperature.
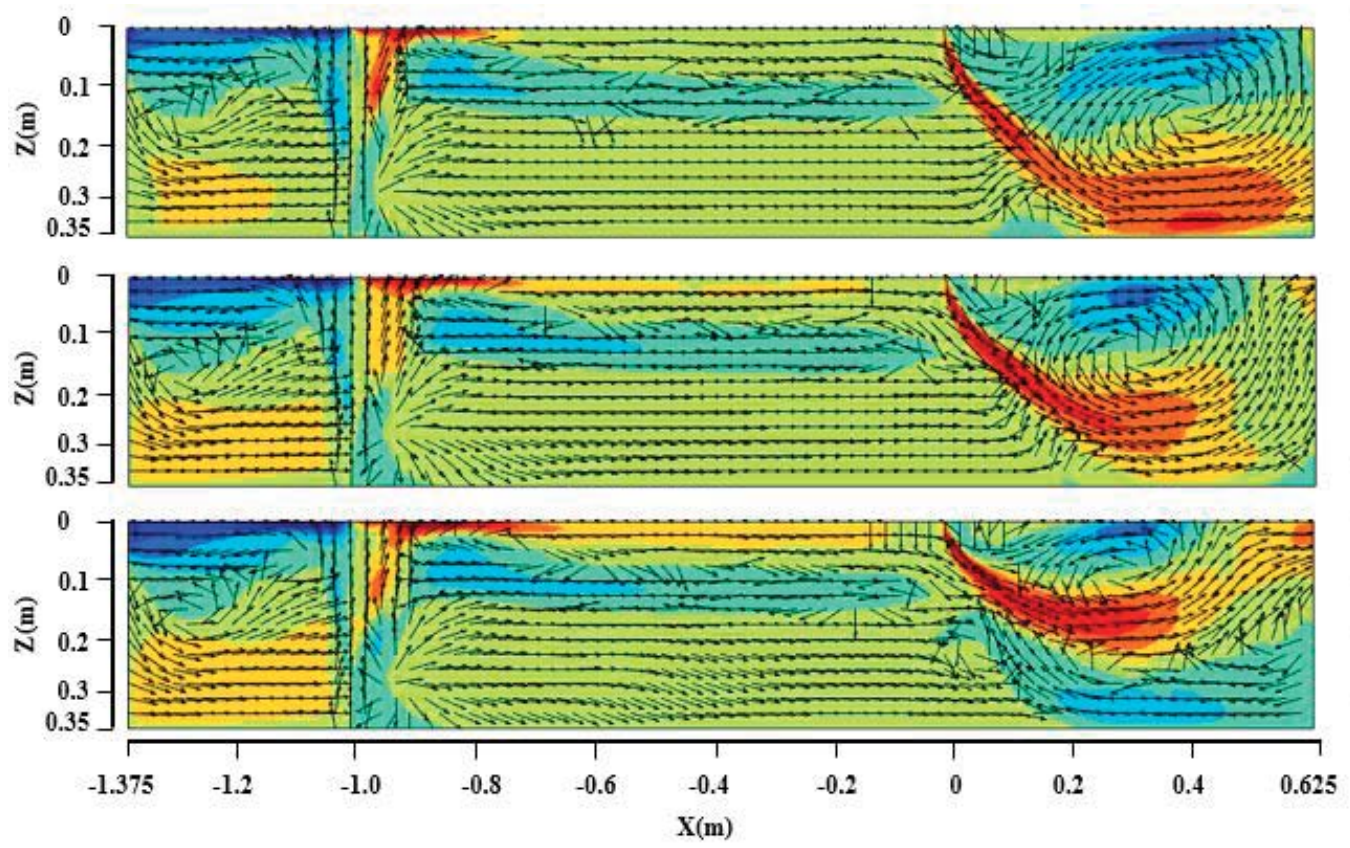

Figure 10. Mean horizontal velocity contours in the symmetry plane of the wind tunnel.

$U>0$ represents flow to the right; $U<0$ represents flow to the left. From top to bottom: plume inlet temperature equal to $150^{\circ} \mathrm{C}, 300^{\circ} \mathrm{C}$ and $600^{\circ} \mathrm{C}$. The air curtain maximum 
inlet velocity is $V_{j}=0.75 \mathrm{~m} / \mathrm{s}$.

Figure 10 presents contour plots of the mean horizontal velocity, as well as the velocity vectors, in the symmetry plane of the wind tunnel for the three hot smoke inlet temperatures. Clearly a stronger deflection of the air curtain flow is observed for higher smoke inlet temperature, due to the increased horizontal momentum (see Table 2).

Not surprisingly, as explained above (for figures 6 and 7), this is also reflected in the contour plots for mean temperature. Indeed, Figure 11 reveals clearly again that the temperature rise behind the air curtain becomes less for higher values of $R$.
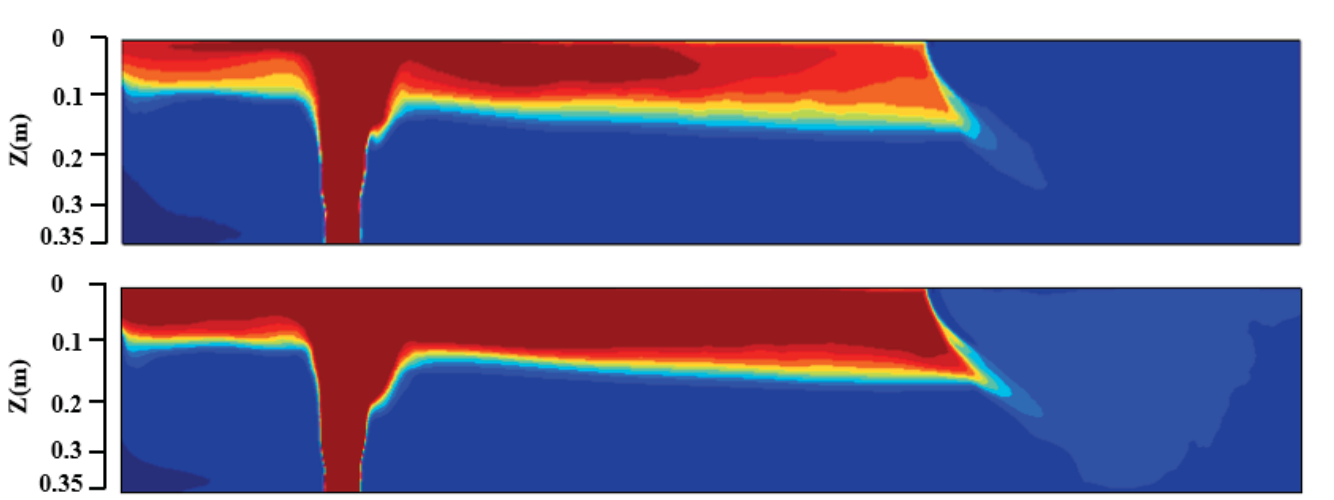

$\mathbf{T}\left({ }^{\circ} \mathrm{C}\right)$
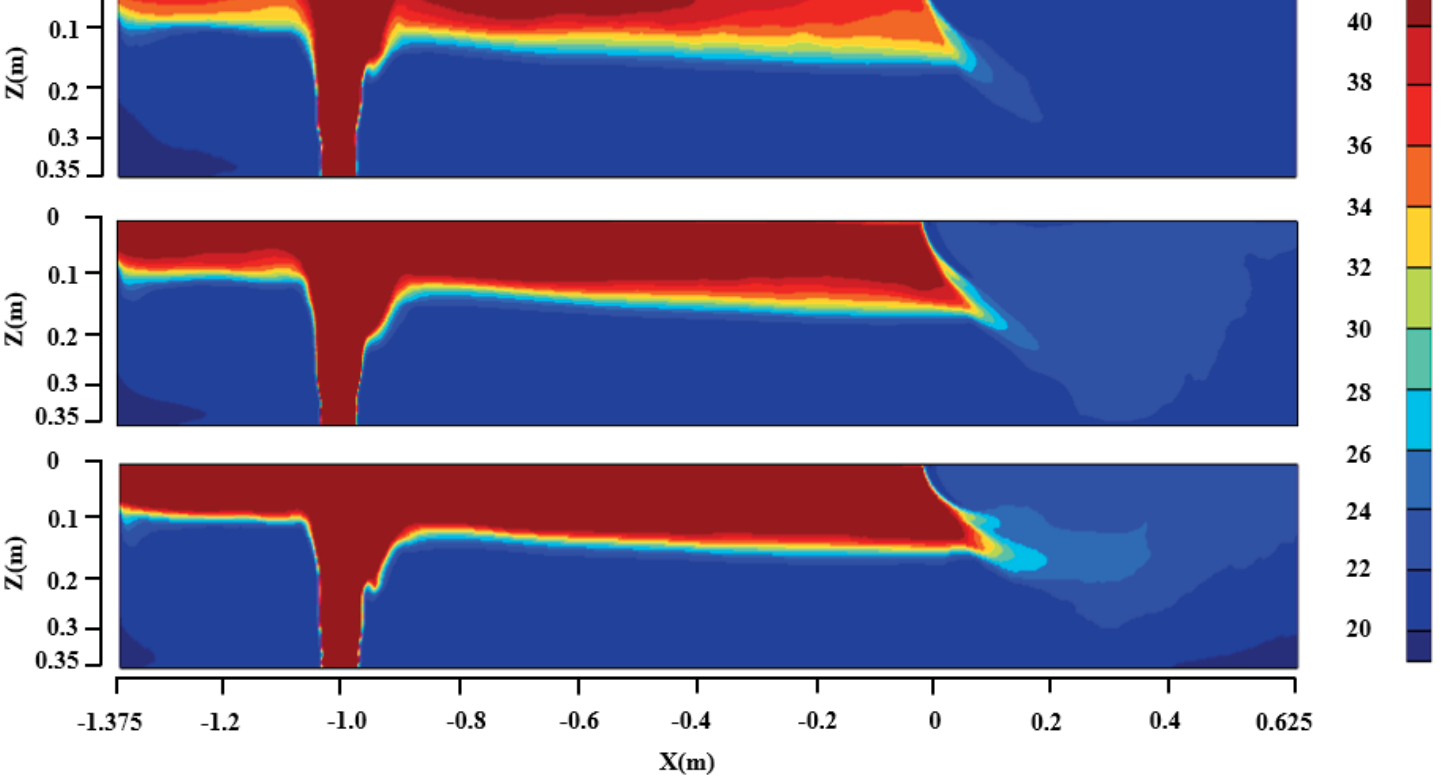

Figure11. Mean temperature contours in the symmetry plane of the wind tunnel. From top to bottom: plume inlet temperature equal to $150^{\circ} \mathrm{C}, 300^{\circ} \mathrm{C}$ and $600^{\circ} \mathrm{C}$. The air curtain maximum inlet velocity is $V_{j}=0.75 \mathrm{~m} / \mathrm{s}$. 
Figure 12 further quantifies the results presented in Fig. 11, by means of mean temperature profiles. These can be compared to Figures 4 and 8 . Both in front of and behind the air curtain, higher smoke layer temperatures are observed for higher smoke inlet temperature, as expected. However, the smoke layer interface height in between the smoke plume and the air curtain is to a large extent independent of the smoke inlet temperature. It is clearly thicker than when the air curtain is not activated (Fig. 4), as discussed above for Fig. 8.
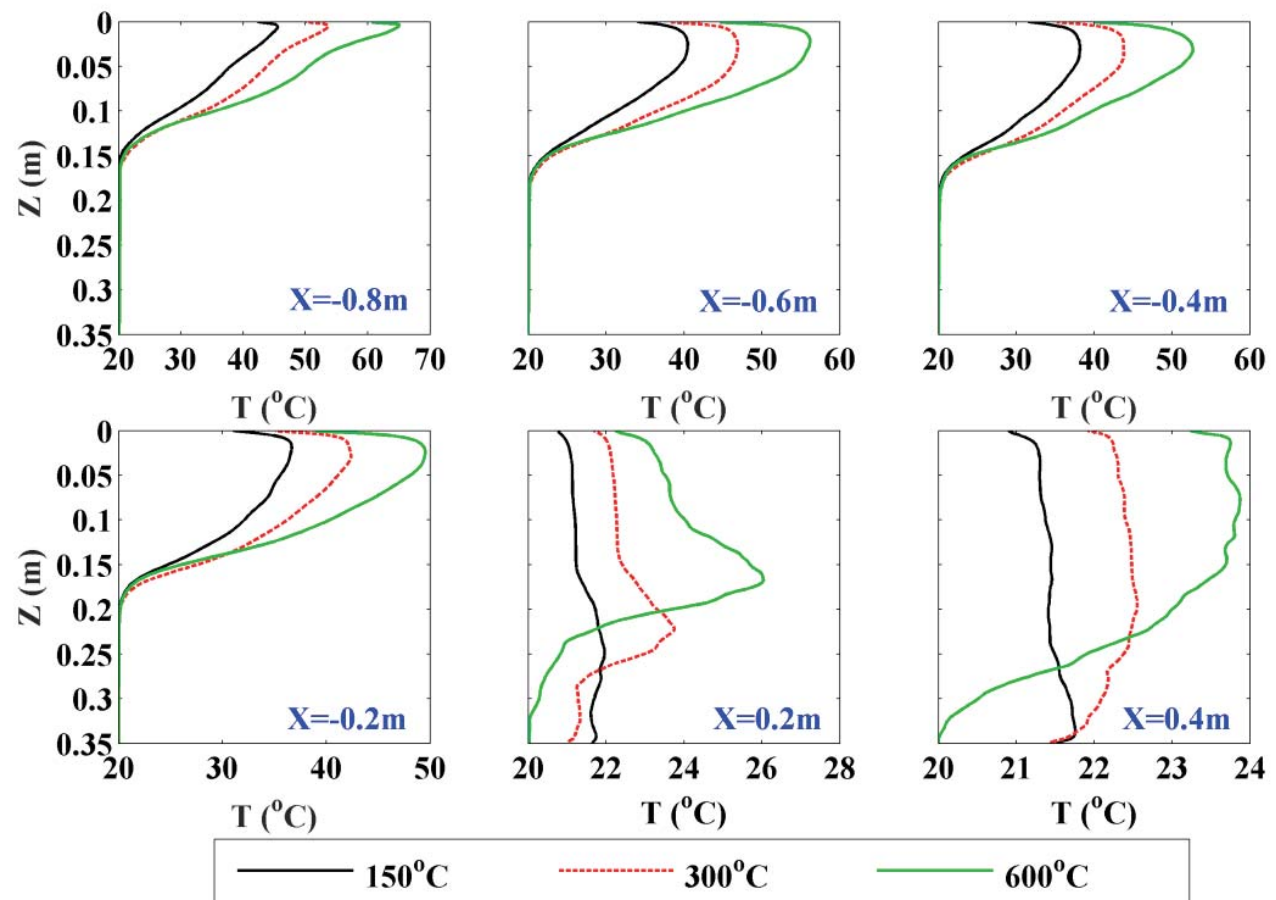

Figure 12. Vertical profiles of mean temperature at different locations in the symmetry plane of the wind tunnel. The legend refers to the plume inlet temperature (in ${ }^{\circ} \mathrm{C}$ ). The air curtain maximum inlet velocity is $V_{j}=0.75 \mathrm{~m} / \mathrm{s}$.

\subsection{Sealing effectiveness of a vertical-downward air curtain}

The performance of an air curtain, i.e., its ability to reduce the heat and mass transfer, is usually assessed in terms of sealing effectiveness [18]. The effectiveness $E$ is defined here 
in terms of the difference between the overall temperature rise, $\Delta T_{V_{j}}$, obtained from integration over the volume downstream of the air curtain, and the reference value, $\Delta T_{V_{j}=0}$, when the air curtain is absent:

$$
E=1-\frac{\Delta T_{V_{j}}}{\Delta T_{V_{j}}=0}
$$

$\Delta T_{V_{j}}$ has been calculated as:

$$
\Delta T_{V_{j}}=\frac{1}{V} \int\left(T_{V_{j}}(x, y, z)-T_{a m b}\right) d x d y d z
$$

where $V$ is the downstream volume over which the integrated temperature rise is calculated, i.e., the entire tunnel space behind the air curtain from $X=0.025 \mathrm{~m}$ to the end of tunnel $X=0.625 \mathrm{~m}$ (see Figure 2). The reason for choosing the boundary of the volume $0.025 \mathrm{~m}$ downstream of the center of the air curtain is to leave out the influence of air curtain. In Eq. (3), $T_{V_{j}}(x, y, z)$ is the temperature at location of $(x, y, z)$ and $T_{a m b}$ is the ambient temperature $\left(T_{a m b}=20^{\circ} \mathrm{C}\right)$.

Table 3 shows the sealing effectiveness values of all the tests in the present study.

Table 3. Effectiveness of air curtain for all test cases (in \%). Top row: air curtain maximum inlet velocity (in m/s); left column: smoke plume inlet temperature (in ${ }^{\circ} \mathrm{C}$ ).

\begin{tabular}{|l|c|c|c|c|c|c|c|c|c|c|}
\hline & $\mathbf{0 . 5}$ & $\mathbf{0 . 7 5}$ & $\mathbf{1}$ & $\mathbf{1 . 2}$ & $\mathbf{1 . 4}$ & $\mathbf{1 . 5}$ & $\mathbf{1 . 6}$ & $\mathbf{1 . 8}$ & $\mathbf{1 . 9}$ & $\mathbf{2}$ \\
\hline $\mathbf{1 5 0}$ & & 51.3 & 59.9 & 47.4 & 42.9 & 42.4 & 43.6 & & & \\
\hline $\mathbf{3 0 0}$ & 36.2 & 46.1 & 57.4 & 50.7 & 43.4 & 41.4 & 36.1 & 34.7 & 46.0 & 53.9 \\
\hline $\mathbf{6 0 0}$ & & 44.0 & & 52.4 & & 41.2 & & & & 42.6 \\
\hline
\end{tabular}

Figure 13 shows the relationship between the sealing effectiveness $E$ and the momentum ratio $R$. The sealing effectiveness $E$ increases as the momentum ratio $R$ increases. The maximum effectiveness is attained for $R=8-10$. This increase of sealing effectiveness is due to the increased blocking effect of the air curtain as the momentum ratio $R$ increases. 
A decrease in the effectiveness is subsequently observed in the range $R=10-25$. The reason is that the higher momentum of the air curtain causes a stronger impinging jet onto the floor, pushing smoke into the downstream region, as shown in Figure 7: for air curtain with $\mathrm{V}_{j}=1.5 \mathrm{~m} / \mathrm{s}$, there is a larger region with (moderately) higher temperatures downstream the air curtain than with $V_{j}=1 \mathrm{~m} / \mathrm{s}$. This indicates a drawback of the use of vertically downward air curtains.

An increase in the effectiveness is observed again if $R$ continues to increase, as shown for $R>25$. The reason is dilution of the smoke, not only by the air curtain itself, but also because a significant amount of (fresh) air is entrained into the domain from the right opening (see the last figure of Figure 5).

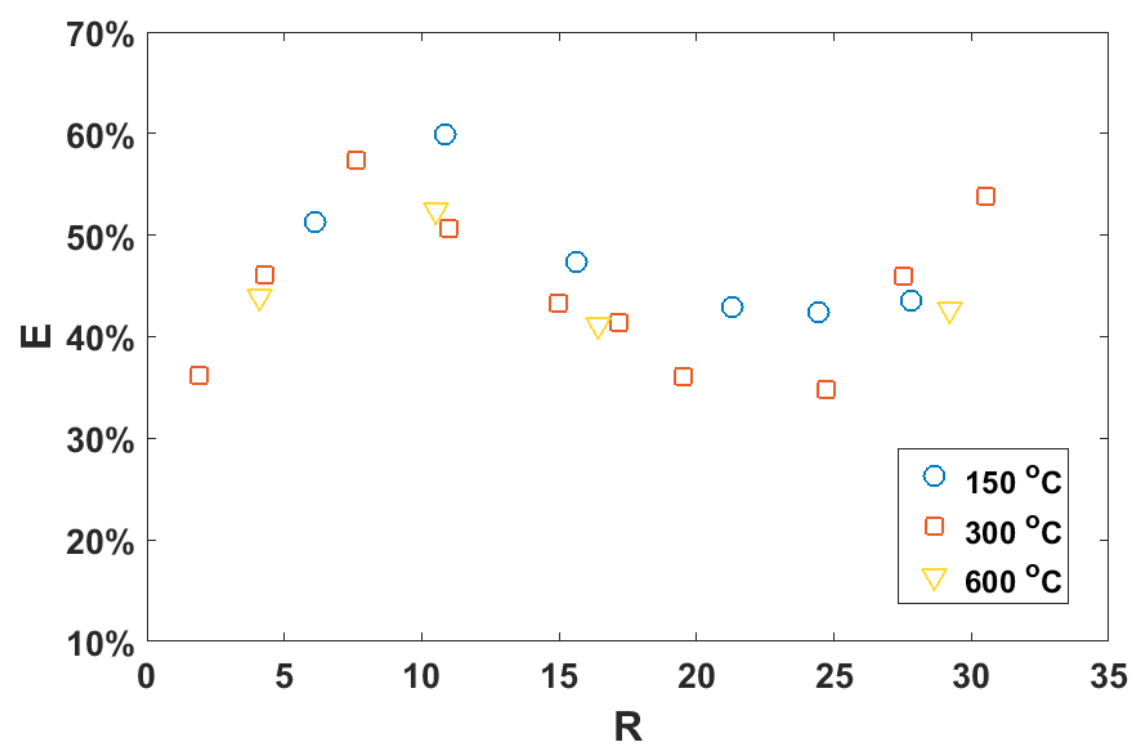

Figure 13. Air curtain sealing effectiveness $E$ vs momentum ratio $R$

\section{Conclusions}

FDS (6.0.1) CFD simulation results of smoke flow and temperature fields in a wind tunnel, under the effect of an air curtain for smoke blocking, have been discussed. A range of air 
curtain inlet velocities and smoke inlet temperatures have been considered.

The results have been presented in a non-dimensional manner, through the quantity $R$ (Eq. (1)), expressing an 'effective momentum ratio', based on ratio of the vertically downward momentum of the air curtain to the horizontal momentum of the hot smoke layer underneath the ceiling at the position of the air curtain.

The performance of an air curtain is expressed as the sealing effectiveness $E$. For small values of $R$, the sealing effectiveness $E$ increases as the momentum ratio $R$ increases. A maximum air curtain sealing effectiveness, $\mathrm{E} \approx 60 \%$, is attained for $R=8-10$ for the case at hand. It is not recommended to apply higher values of $R$, since this reduces the sealing effectiveness. For very high values of $R$ the effectiveness increases again, due to dilution of the smoke that is pushed in the downward region. Note that high values of $R$ can also lead to additional oxygen supply to the fire seat, due to the impingement on the floor, which can be hazardous in case of under-ventilated fires.

The maximum value of the sealing effectiveness being only $60 \%$ indicates that the use of vertical air curtains is not recommended. The reason for that is that the vertical momentum of the air curtain cannot directly compete with the horizontal momentum of the smoke motion.

In case of an air curtain in operation, smoke accumulates upstream of the air curtain, resulting in higher temperatures and a descent of the smoke layer interface height, compared to the situation without air curtain. This can be a drawback.

The air curtain flow is deflected by the horizontal momentum of the smoke. The deflection becomes less for higher air curtain jet velocity, for a given level of smoke momentum (i.e., for given smoke inlet temperature, in a given geometry). Similarly, the deflection becomes 
more pronounced for higher smoke inlet temperature, given a certain air curtain velocity. Indeed, the higher smoke inlet temperature increases the horizontal momentum of the smoke layer, due to increased energy injection and increased buoyancy (and thus increased entrainment in the vertical smoke plume).

\section{Acknowledgements}

This research has been conducted at Ghent University, supported by the State Scholarship Fund of China under grant No.201306050081 and Chongqing Graduate Student Research Innovation Project under grant No.CYB14031.

Dr. Tarek Beji is Postdoctoral Fellow of the Fund of Scientific Research - Flanders (Belgium) (FWO-Vlaanderen)

The computational resources (Stevin Supercomputer Infrastructure) and services used in this work were provided by the VSC (Flemish Supercomputer Center), funded by Ghent University, the Hercules Foundation and the Flemish Government - department EWI.

\section{References}

1. Sakurai H, Hayashi T, Shibata M, Kanehara K (1980) Researches on air shutter for fire defence. Fire Safety Journal 2 (1):9-16. doi:10.1016/0379-7112(79)90011-0

2. Etkin B, Goering PLE (1971) Air-Curtain Walls and Roofs-'Dynamic' Structures. Philosophical Transactions of the Royal Society of London Series A, Mathematical and Physical Sciences 269 (1199):527-543. doi:10.1098/rsta.1971.0050

3. Frank D, Linden PF (2014) The effectiveness of an air curtain in the doorway of a ventilated building. Journal of Fluid Mechanics 756:130-164. doi:10.1017/jfm.2014.433 
4. Foster AM (2007) CFD Optimization of Air Movement through Doorways in Refrigerated Rooms. In: Computational Fluid Dynamics in Food Processing. Contemporary Food Engineering. CRC Press, pp 167-193. doi:10.1201/9781420009217.ch7

5. Guyonnaud L, Solliec C, de Virel MD, Rey C (2000) Design of air curtains used for area confinement in tunnels. Experiments in Fluids 28 (4):377-384.

doi:10.1007/s003480050397

6. Elicer-Cortés JC, Demarco R, Valencia A, Pavageau M (2009) Heat confinement in tunnels between two double-stream twin-jet air curtains. International Communications in Heat and Mass Transfer 36 (5):438-444. doi:10.1016/j.icheatmasstransfer.2009.01.019 7. McGrattan KB, Hostikka S, Floyd J (2015) Fire Dynamics Simulator, User's Guide. NIST Special Publication 1019, Sixth edn. National Institute of Standards and Technology, USA. doi:10.6028/NIST.SP.1019

8. Hu LH, Fong NK, Yang LZ, Chow WK, Li YZ, Huo R (2007) Modeling fire-induced smoke spread and carbon monoxide transportation in a long channel: Fire Dynamics Simulator comparisons with measured data. Journal of Hazardous Materials 140 (12):293-298. doi:10.1016/j.jhazmat.2006.08.075

9. Luo N, Li A, Gao R, Zhang W, Tian Z (2013) An experiment and simulation of smoke confinement utilizing an air curtain. Safety Science 59 (0):10-18. doi:10.1016/j.ssci.2013.04.009 10. Debeer C (2015) Low Speed Wind Tunnel L-2B. Vki.ac.be. https://www.vki.ac.be/index.php/research-consulting-mainmenu-107/facilities-other- 
menu-148/low-speed-wt-other-menu-151/60-low-speed-wind-tunnel-1-2b. Accessed 6 July 2015

11. Horvath IA, Buchlin J-M (2012) Extreme PIV applications: simultaneous and instantaneous velocity and concentration measurements on model and real scale car park fire scenarios. Rhode-St-Genèse, Belgium

12. Yu L-X, Liu F, Merci B (2015) Analysis of the impact of the inlet boundary conditions in FDS results for air curtain flows in the near-field region, Ninth Mediterranean Combustion Symposium. Rhodes, Greece

13. Munson BR, Young DF, Okiishi TH (1990) Fundamentals of fluid mechanics. Wiley, New York

14. Jarrin N, Prosser R (2008) Synthetic inflow boundary conditions for the numerical simulation of turbulence. University of Manchester, United Kingdom

15. Tilley N, Rauwoens P, Merci B (2011) Verification of the accuracy of CFD simulations in small-scale tunnel and atrium fire configurations. Fire Safety Journal 46 (4):186-193. doi:10.1016/j.firesaf.2011.01.007

16. McGrattan K, Hostikka S, Floyd J, Mell W, McDermott R (2015) Fire dynamics simulator, technical reference guide, volume 1: mathematical model. NIST Special Publication 1018, Sixth edn. National Institute of Standards and Technology, USA. doi:10.6028/NIST.SP.1018-1

17. Alpert RL (2002) Ceiling jet flows. In: SFPE handbook of fire protection engineering. 3rd edn. National Fire Protection Association, Massachusetts, pp 2-18-1231. doi:10.1007/978-1-4939-2565-0 
18. Costa J, Oliveira L, Silva M (2006) Energy savings by aerodynamic sealing with a downward-blowing plane air curtain - a numerical approach. Energy and Buildings 38 (10):1182-1193. doi:10.1016/j.enbuild.2006.02.003 